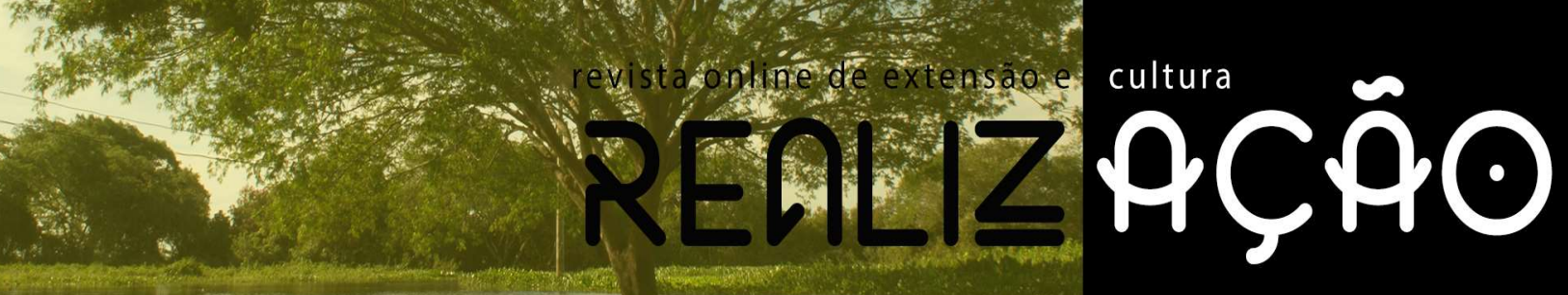

\title{
APOMS'S WEBSITE DEVELOPMENT, ONLINE AGRO ECONOMIC AND/OR ORGANIC PRODUCTS ONLINE STORE
}

DOI: 10.30612/re-ufgd.v6i11.8862

\author{
Fernando Koji Yamashiro ${ }^{1} *$, \\ Otávio Augusto Paganotti Messias da Silva*, \\ Euclides Reuter de Oliveira†, Felipe José Carbone \$, \\ Alexandre Rodrigues Nettho $\S$,

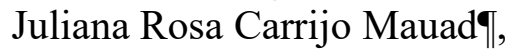 \\ Andréa Maria de Araújo Gabriel†, \\ Jefferson Rodrigues Gandra $\dagger$, \\ Olácio Mamoru Komori k, Thaís Lemos Pereira $* *$, \\ Nara Medeiros Pordeus $* *$
}

Recebido: 01/10/2018Ａceito: 24/08/2019

\begin{abstract}
On the current economic situation, an institution that seeks growth will, at a certain point of its development, have to be accessible on the internet to spread its beliefs and/or products to possible consumers through geographically long distances, that wouldn't be possible in the past as fast as it is now, for this reason APOMS -'Associação de Produtores Orgânicos de Mato Grosso do Sul' was looking for a website, which, now, is being provided by UFGD - 'Universidade Federal da Grande Dourados' through a academic project that aims the learning of students and other people from different university courses. The site acts as a platform for selling organic and/or agro economic products of high quality from its production till the consumer's home, besides being a way of giving a proper destination to products grown by small scale family farmers together with people involved to academic projects from UFGD, some of those provided by PROEXT, PROEX and CNPq. This activity is going to bring product directly to consumers, instead of passing by marketing intermediaries, making the commercial process faster and increase the accessibility to those organic and/or agro economic products. This paper describes the approaches done till this moment on the website.
\end{abstract}

Keywords: User Experience. Familiar agriculture. Design.

$1 * U F G D$ - "Universidade Federal da Grande Dourados", computer engineering's graduate students †UFGD - "Universidade Federal da Grande Dourados", FCA - "Faculdade Ciências Agrárias" professor $\$ U F G D$ - "Universidade Federal da Grande Dourados", FACET "Faculdade de Ciências Exatas e Tecnologia" professor §UFGD - "Universidade Federal da Grande Dourados", mathematics's graduate student I PROEX -"Pró-Reitoria de Extensão e Cultura da UFGD" director. kAPOMS's directory member **UFGD - "Universidade Federal da Grande Dourados", Zootechnic's post graduate students.

Yamashiro et al, p. 26-33 


\section{Introduction}

To a great amount of people internet is undeniably essential asset to their everyday life, basically it is a technology that enables the communication between large groups of people. Had one being put aside from this technological context, that result in an exclusion from our economic system and our cultural society. The speed in which the internet had spread around the globe could due to the fact that, organizationally speaking, it is a flexible and highly adaptable, some remarkably characteristics to survive into an high speed development environment (3).

Internet provided a fast development of the human kind since the beginning of its use, as a reason for this, it is a tool which makes the organization of large groups, geographically distant from other, very flexible and adaptable. According to HARARI(9), the surpass of humankind on the race to rule the world in the past was due to those characteristics on the management of large groups of its species, differently from their counterparts that usually managed small groups flexibly or managed large groups in a very stiffly way. Since most of the search for information is being done by the use of the Web, all of the big institutions are present in this platform, ranging from social medias to websites, to spread their beliefs to people with the same interests or beliefs and possible customers. To keep up with the competition, every kind of business will have to be present in the internet at some level. Looking forward to the increase of people's awareness on the association that the idea of a website for APOMS - 'Associação de Produtores Orgânicos de Mato Grosso do Sul' came up, and it is being developed as a partnership between them and UFGD - 'Universidade Federal da Grande Dourados'.

APOMS is an association legally formed in 2000, aiming for a sustainable form of agriculture of family farmers according to agroecological processes, fastening the associates bond. At this moment, 2018, there are almost 170 families, small scale farmers from a variety of backgrounds, e.g. brazilian indians population, owners of lands from the land reform. To be present in multiple areas of the state, APOMS is organized in administrative nuclei spread around Mato Grosso do Sul, doing the certification process, training and teaching in organic and/or agro economic processes of its members. People are being more and more aware of APOMS, even internationally, owing to the positive impacts of its actions on communities and other institutions it is related with, in addition to that, develop activities with third party institutions, such as technical orientation visits, training programs, exchange opportunities, organic and/or agro economic product certification, implementation of demo units, creation and participation of seminars and fairs focused 
on agro ecology and/or organic production, and so on. Nationally speaking, it became a reliable source of information regarding organic and agro ecological production and processes, i.e. it represents forums, is in national and international events and included in decisions of national policies. As a result of its growth, its actions focuses not only in organic production, like in the very beginning of the association, but the development of inclusion on the market though policies of fair trade and solidarity.

UFGD has its involvement by an academic project named "Desenvolvimento de site para Comercialização de Produtos Agroecológicos e/ou Orgânicos Provenientes da Agricultura Familiar", where a website is being made by the university's computer engineering students to sell products (online store), as a goal, will give those students the knowledge to build a website by a real client specifications, giving them the perspective, difficulties and exceptions to what is learned in classes.

WordPress is being used to make the site, following a evolutionary prototyping approach, its is being designed according to APOMS's needs and its target public's profile by some design principles.

First of all, even being an unusual thought, design has its own rules, implicit and explicit ones, because design can be seen as the cognitive and emotional answers that people have to certain stimulus, in other words, the inclusion or change of some elements can cause different cognitive and emotional reactions in a expected way, for this reason it is understandable that rules can be applied on design since we, as a specie, have the some pretty good understanding of the human psychological system.

"Design is Design is Design"(2), it basically says that design, even for differently endings, is design, e.g. a toy's design have the same objective as a website design, in which it is solve the problems that were given, moreover we can apply general design rules, with some appropriate changes, to the creation of the website.

Something more to be worried about the website is the user experience (UX). Basically, can be defined as an approach that seeks for the best experience for the user on his/her website navigation(7). There is the need to have in mind the possible user's profile and how will he/ she interact with the website, therefore UX defines the requirements, and the design rules, the solutions for the website.

\section{Development}




\subsection{Before the website}

There are 3 essential elements to put a website online ${ }^{2}$, domain - the address to use in the internet browser to access the website, host service - where it is going to be stored to send and save data when it is requested and the content - information and its structure. A website could be put online by numerous ways, e.g. buy the host and the domain altogether by only one company, which is set up already or hire a service that gives you the whole website done and its future maintenance.

The domain and the host service were gotten individually, addressed as $<$ https: //apoms.com.br/>, registered through registro.br's service1 and the host service of King Host ${ }^{3}$. So, entering with the address into the internet browser will require the server, where it is stored, the website's code to rendered and be presented to the user, its content is being designed with WordPress, a asset to create website, even though it enriches the website and gives the developer more freedom, there is not exactly a need to be knowledgeable about CSS, HTML or Javascript coding.

\subsection{Development requirements}

Having in mind software engineering (4) and meetings had with APOMS's administrativemembers,somerequirementsweredefined,suchasthefunctionalitiesonthewebsite, the level of depth in the navigation and the data exposure. An evolutionary prototyping approach was chosen, it is an method where the website is getting more and more close to the final product through the evolution of a single prototype enhancing the appearance and the functionalities of it. Another requirement, is to make, not only the online store, but the institutional pages as well to bring awareness around the association's beliefs and values, other pages were defined in the course of the website development.

\subsection{Website}

To start with the use of WordPress, firstly a theme should be chose, essentially it is an template with some predefined styling configurations, after setting it up, a stiff, but functional, website is already available, to increase its functionalities, plugins can be installed giving a sophisticated appearance. The theme chosen to develop the website was the "StoreFront"that works

2 Domain management division of "Comitê Gestor da Internet no Brasil" $<$ https://registro.br/> 3 Host service's webpage $<$ https://king.host/>. 
together with the "WooCommerce"plugin1, enabling the implementation of a online store, some other plugins were installed too to bring functionalities like photo gallery and sliders ("Envira Gallery" and "Smart Slider"), user permission management ("User Role Editor") and website access data control panel functionality (“jetpack”).

Consider the following separations to make the understanding of the design rules(8) applied easily, Homepage (the first page seen by the user on the access of the website), secondary pages (every other page), menu (menu bar that facilitates the navigation on the website), images (rules regarding the images selection) and general rules (rules considered in every aspect of the website).

\subsubsection{General rules}

Those general rules were considered on the design of every part of the website and aims the better UX; Accessibility, all the websites have to give conditions to all the people to navigate through it, even those that have special needs or use different kinds of computer equipment and it have to be done according to $\mathrm{W} 3 \mathrm{C}$ (international community that develops open standards to ensure the long-term growth of the Web)(6); Take into consideration all kind of possible users, their navigation will differ according to their personas and backgrounds, so the design must be thought considering the target public; Text formatting, avoids unnecessary information that may get the user tired and bored or putting very superficial information that may not draw the user attention or meet their needs; The colours should be chosen in a way that their mixture should not cause any kind of discomfort to the user; Content alignment that leads the reader to where you want, making the page reading flow natural, and organising information efficiently because the reader consider information relationships according to their visual display(5). Make the interaction between the website and the user flows in a natural way, effortlessly, displaying what is more expected to be accessed close to each other; Give the impression that the user have all the control over what they are doing even if it is put restrictions of access to them, "forgive"users mistake and prevent them from happening, by making it easy to get back to certain points if they get to a point they cannot continue their navigation and hide the parts the users do not have permission; The navigation has to be as easy as possible, otherwise it is highly likely that the user will not access it again; Consider whether the visual aspect and functionalities are balanced not compromise each other.

\subsubsection{Homepage}


The homepage is the most important page, it will give the user the first and so defining impression, so the proportion of images to texts needs to be fair. There are some ${ }^{4}$ techniques of content exposure to build a specific opinions that were applied on the design to make the user associate APOMS with health; Because only $20 \%$ of the page will build most of an user's opinion, it is important to chunk all the important information well aligned on the home page.

\subsubsection{Secondary Pages}

Besides the homepage, that only has to call attention, all the pages have to display specific information, making the use of text organisation and images selection and arrangement; How new content will be described, comparing to other pieces of information or describe in details, according to the ease each of them will bring; The consistency of the pages should remain, in order to avoid discomfort of the reader.

\subsubsection{Menu}

On this part the rules basically aim the organisation of information to make the navigation between pages easier, and lead the user to the king of information he/she wants, trying to have a good amount of pages, big enough to hold all the necessary information and small enough to give the user coherent options, the more the options the more time he/she would take to make a decision, and it goes on the other direction of a effortless navigation.

\subsubsection{Images}

The image selection had some criteria regarding the message it would send to the user and the feelings it would bring; Whether the image should have people in it, and if it does, the proportion of body to face; The lights on the photos to appear as natural as possible; Third's rule, rule highly used in photograph that projects grids into an image and the elements should be spread evenly onto it.

\section{Website's Future}

There are still some pages that need to be filled with content, but it is already decided which pages are going to be present in the APOMS's website, the Homepage, one page to describe each, the association, the commercial cooperative, the certifier, training centre, nuclei, values, 4 WordPress's plugin webpage $<$ https://woocommerce.com/storefront/ $>$ 
structural projects and educational projects adding to it pages of written references and family stories, online store and contact. It will be necessary to train website operators from APOMS, in which it will be a training module or a written guide of operations. After the conclusion on the website development, the effectiveness will be tested and evaluated according to feedbacks from test groups.

\section{Conclusion}

The website is not completely content filled and missing some text formatting and image arrangement in order to improve the UX and design. However, the main goal of this activity was achieved, the development of the website under real circumstances and client's requirements, taking as a lesson the difficulties in managing the client's needs and wishes to the rules, even though those are not definitive, they are necessary. The knowledge acquired in this project is intended to be passed on to other students and the community involved on the development of this website, fastening the bond between educational institutions in general.

\section{Thanks}

Thanks to the PROEX - "Pró-Reitoria de Extensão e Cultura da Universidade FederaldaGrandeDourados-UFGD,"Núcleodeconstruçãoparticipativadoconhecimento

Agroecologia e Produção Orgânica da UFGD", "Centro vocacional tecnológico em Agroecologia e Produção Orgânica, em Mato Grosso do Sul da UFGD", APOMS- "Associação de Produtores Orgânicos de Mato Grosso do Sul", MEC - "Ministério da Educação"and CNPq - "Conselho Nacional de Desenvolvimento Científico e tecnológico".

\section{References}

PUBLISHING your website, MDN web docs, Last update: 2018 June, link: $<$ https://developer.mozilla.org/en-US/docs/Learn/Getting_started_with_the_web/ Publishing_your_website>,accessed: 2018 may. Citado na página 3.

Joe Natoli, [curso] User Experience Design Fundamentals,Udemy platform, 2015, link: $<$ https://www.udemy.com/user-experience-design-fundamentals/>, accessed: 2018 August, 21. Citado na página 3.

Manuel Castells, The Internet Galaxy: Reflections on the Internet, Business, and Society, Oxford University Press,Oxford NY, 2001. Citado na página 2. 
